\title{
Exploring the abomasal lymph node transcriptome for genes associated with resistance to the sheep nematode Teladorsagia circumcincta
}

\author{
Anton Gossner, Hazel Wilkie, Anagha Joshi and John Hopkins
}

\begin{abstract}
This study exploited Blackface lambs that varied in their resistance to the abomasal nematode parasite, Teladorsagia circumcincta. Infection of these lambs over 3 months identified susceptible (high adult worm count, high faecal egg count and low IgA antibody) and resistant animals that had excluded all parasites. Previous work had shown that susceptibility and resistance is dependent on the differential immune response to the parasite, which occurs within the abomasal (gastric) lymph node (ALN) that drains the site of infection. The Affymetrix ovine gene array was used to interrogate the transcriptome of the ALN to identify genes and physiological pathways associated with resistance. We used a bovine RT-qPCR array of 84 genes to validate the gene array, and also report digital gene expression analysis on the same tissues, reanalysed using the Oar v3.1 sheep genome assembly. These analyses identified Humoral Immune Response, Protein Synthesis, Inflammatory Response and Hematological System Development and Function as the two top-ranked networks associated with resistance. Central genes within these networks were IL4, IL5, IL13RA2 and in particular IL13, which confirmed that differential activation of Th2 polarized responses is critical to the resistance phenotype. Furthermore, in resistant sheep there was up-regulation of genes linked to control and suppression of inflammation. The identity of differentially-expressed chemokines and receptors in the resistant and susceptible sheep also begins to explain the cellular nature of the host response to infection. This work will greatly help in the identification of candidate genes as potential selectable markers of genetic resistance.
\end{abstract}

\section{Introduction}

Gastrointestinal nematode parasites are the cause of major economic losses to the sheep agricultural industry [1] and the major species in cool temperate regions is the abomasal strongylid Teladorsagia circumcincta $[1,2]$. The control of this parasite is largely by the use of broad-spectrum anthelmintics $[3,4]$ but the increasing incidence of drug-resistant parasites and concern of drug residues in meat [5] has led to the search for alternative methods of parasite management [6]. The animals most susceptible to T. circumcincta are weaned lambs [7]. Most lambs eventually suppress infection [8] through the development of IgE and IgA anti-parasite

\footnotetext{
*Correspondence: john.hopkins@ed.ac.uk

The Roslin Institute \& R(D)SVS, University of Edinburgh, Easter Bush, Midlothian EH25 9RG, UK
}

antibodies; but this takes more than 6 weeks of persistent infection with infectious larvae [9-11]. Mucosal mast cells have also been shown to play an important role in the limitation of larval colonization and expulsion of helminths [12,13] and these also function largely in association with parasite-specific antibodies [14]. However, some sheep in most flocks develop only low levels of helminth-specific antibodies and fail to control larval colonization and egg production. Indeed, IgA levels and faecal egg counts (FEC) have been used as selectable markers for resistance $[8,15,16]$. Furthermore, different sheep breeds show marked diversity in resistance to helminth infection [17-19]. Consequently, one strategy for the non-pharmacological control of parasites is the exploitation of genetic variation for 
resistance found within and between different sheep breeds $[20,21]$.

Selection for resistance can be based on quantitative measurements of one or more phenotypic traits such as FEC and IgA antibody levels $[16,22]$ but the identification of molecular markers is potentially a more reliable approach for high resolution selection [23]. There are three approaches for the identification of such markers, quantitative trait locus (QTL) mapping, genome-wide association studies (GWAS) and candidate gene analysis [24]. QTL mapping is of low power and requires extensive further work to identify candidate genes [25]. GWAS is expensive, requiring very large numbers of samples; in addition, lack of current sheep genomic resources mitigates against high resolution analysis [26]. The alternative candidate gene approach aims to evaluate the relationship between a phenotypic trait and a variation in a gene; this gene is selected by measuring differential expression in relation to a relevant phenotype. A number of studies have used sheep microarrays to identify genes and molecular pathways associated with host responses to abomasal nematode parasites in sheep. Most have analysed the transcriptome of the Haemonchus contortus or T. circumcincta infected abomasal mucosa [27-29] or afferent lymph cells draining that mucosa [30]. In addition, a RT-qPCR assay has been developed to analyse a limited number of immune-inflammatory genes [31]. However, the immune response to parasites in the abomasum takes place within the abomasal (gastric) lymph node (ALN) and the events within that node determine the quality and quantity of the immune response and consequently the clinical outcome of infection.

This current study exploited parasite-naïve Blackface lambs with diversity in their predicted genetic resistance to $T$. circumcincta, which were trickle-infected with L3 larvae to mimic natural infection [32]. This regime resulted in lambs with a range of resistance as assessed by adult worm counts, FEC and IgA levels. Previous studies with these sheep used digital gene expression (DGE) [24] and RT-qPCR [33] to conclude that both resistance (no FEC/high IgA) and susceptibility (high FEC/ low IgA) are active responses to infection; and that the inflammatory lesions of the susceptible sheep are associated with differential activation of Th17 T cells. Consequently the aim of this project was to investigate genes and physiological pathways associated with the differential activation of the immune response linked to the different disease outcomes. These pathways are likely to contain candidate genes as potential selectable markers for resistance to $T$. circumcincta infection. However, in this new study we use the novel Affymetrix Ovine Gene 1.1 ST whole-genome array, based on the homologous Oar v2.0 assembly, and focus on gene and pathway identity in relation to resistance and susceptibility.

\section{Materials and methods}

\section{Animals and experimental design}

Fifty-five female Blackface lambs (10-13 weeks old), from a flock previously used for quantitative genetic and QTL analyses [23], were housed in worm-free conditions. Ten lambs were sham infected controls; 45 lambs were infected experimentally with $\sim 2300$ infective L3 T. circumcincta larvae three times a week for 12 weeks and sacrificed two days after the last infection. The sham-infected controls (C) were twins of lambs in the infected group. At post mortem ten infected lambs had no detectable adult worms in the total abomasal contents, while the other infected lambs had a range of adult worm counts up to 11300 . The lambs selected for analysis were chosen to maximize the power of detecting differential expression. Consequently, animals were ranked according to their infection levels [32]. The 7 most resistant lambs $(\mathrm{R})$ had no detectable abomasal adult worms or faecal egg count (FEC), high IgA antibody levels and high body weight. The 7 most susceptible lambs $(\mathrm{S})$ were those with the highest adult worm count (mean 6000, maximum 11 300), high FEC (mean 414, maximum 950), low IgA antibody levels and low body weight. Details of the animals, infection protocols, trait and population genetic analyses have been described previously $[32,33]$. Animal experiments were approved by University of Edinburgh Ethical Review Committee and conducted under an Animals (Scientific Procedures) Act 1986 Project Licence.

\section{Sample collection and total RNA isolation}

Abomasal (gastric) lymph nodes (ALN) were removed immediately post mortem and stored at $-80^{\circ} \mathrm{C}$ in RNAlater (Ambion, Huntingdon, UK). Total RNA was isolated using the Ribopure Kit (Ambion) as described previously [32]. RNA quality and integrity were assessed using a RNA 6000 Nano LabChip on the Agilent 2100 Bioanalyzer and quantified using a NanoDrop ND-1000 spectrophotometer; all had an RNA Integrity Number of $>7.5$.

\section{Whole-transcript expression analysis and profiling}

Primary transcriptome analysis was by Affymetrix Ovine Gene 1.1 ST Array. Sense-strand cDNA was generated from total RNA (500 ng) subjected to two rounds of amplification (Ambion ${ }^{\circ}$ WT Expression Kit). The obtained cDNA was used for biotin labelling and fragmentation by Affymetrix GeneChip ${ }^{\circ}$ WT Terminal Labelling and Hybridization kit (Affymetrix). Biotin-labelled fragments of cDNA $(5.5 \mu \mathrm{g})$ were hybridized to Affymetrix Ovine Gene 1.1 ST Array plates using the appropriate HybWash-Scan protocol for this plate and the Gene Titan Hyb Wash Stain kit for the reagents (Affymetrix). After hybridization every array plate was washed and stained before the array plates were scanned by the Imaging Station 
of GeneTitan System. Image generation and the resulting CEL files for analysis were produced in Affymetrix ${ }^{\circ}$ GeneChip ${ }^{\oplus}$ Command Console ${ }^{\oplus}$ Software (AGCC) version 3.0.1. Initial QCs were performed in Expression Console. The obtained Affymetrix .CEL files were imported into the Genomics Suite software package version 6.13.0213 (Partek, St. Louis, MO, USA). The imported data were analysed at the gene-level, with exons summarized to genes, using the mean expression of all the exons of a gene. Background correction was carried out using the robust multiarray average (RMA) algorithm, with quantile normalization, median polish probe summarization, and $\log 2$ probe transformation. Differentially expressed genes were identified by ANOVA, genes with a fold change $>1.5$ or $<-1.5$, and a false discovery rate $($ FDR $)>0.05$ were kept, calculated using the Benjamini-Hochberg method to adjust $P$-values [34]. Gene annotation was performed based on similarity scores in BLASTN comparisons against ovine or bovine sequences in GenBank.

Inflammatory cytokines \& receptors RT2 profiler $^{\mathrm{TM}} \mathrm{PCR}$ array Quantitative real-time RT-PCR (RT-qPCR) analysis was performed using the SABiosciences Cow Inflammatory Cytokines \& Receptors RT2 Profiler ${ }^{\mathrm{TM}}$ PCR Array (Qiagen, Crawley, UK), which measures the expression of 84 genes that mediate the inflammatory response (Cat. no. 330231 PABT-011ZR). Total RNA was extracted as described above and treated with RNase-free DNase I (Qiagen) and RNeasy MinElute Cleanup Kit (Qiagen) according to the manufacturer's protocol to eliminate DNA contamination. Each $0.8 \mu \mathrm{g}$ sample of RNA was reverse transcribed using a $\mathrm{RT}^{2}$ First Strand Kit (Qiagen) before dilution with RNase-free water according to the manufacturer's protocol. A real time PCR was performed on each cDNA sample using the $\mathrm{RT}^{2}$ Profiler $^{\mathrm{rm}}$ PCR Array with the $\mathrm{RT}^{2}$ SYBR Green ROX FAST Mastermix on a Rotor-Gene Q cycler (Qiagen). The cycling profile was performed at $95^{\circ} \mathrm{C}$ for $10 \mathrm{~min}$, followed by 40 cycles of $95^{\circ} \mathrm{C}$ for $15 \mathrm{~s}$ and $60^{\circ} \mathrm{C}$ for 1 min. Melting curve analysis of PCR products confirmed the absence of secondary product. $\mathrm{RT}^{2}$ Profiler PCR Array Data Analysis v3.5 was used for data analysis. The data analysis was based on the $\Delta \Delta \mathrm{Ct}$ method with gene expression normalized to the reference gene YWHAZ.

\section{Cloning of ovine gene fragments}

Amplicons from the $\mathrm{RT}^{2}$ Profiler $^{\mathrm{TM}}$ PCR Array were cloned and sequenced to confirm PCR primer specificity using the $\mathrm{TOPO}^{\oplus} \mathrm{TA}^{-}$Cloning ${ }^{\oplus}$ Kit for Sequencing (Life Technologies) and BigDye ${ }^{\oplus}$ Terminator v3.1 Cycle Sequencing Kit (Applied Biosystems) according to the manufacturer's instructions. Cloned amplicon sequences were used in BLASTN comparisons against ovine or bovine sequences in GenBank to confirm identity.

\section{Illumina digital gene expression}

Full details of the RNAseq methods and analysis have been described previously [24]. These sheep sequences were originally aligned against the Btau 4.0 bovine genome. Detailed protocols, metadata and all raw data are deposited at the ArrayExpress database [35] accession number E-MTAB-445. For the current study the raw data were reanalysed by alignment against the sheep genome assembly Oar v3.1 [36] using Bowtie v0.12.8 [37]. Only tags with phred mapping quality of at least 30 , with a maximum of one base-pair mismatch and mapped to less than two genome locations were retained for further analysis. Furthermore, only genes that were mapped from five samples or more were included in the final analysis. Statistical analysis was performed using " $\mathrm{R}$ v2.15", and Limma [38] within BioConductor 2.11 [39] was used to calculate the differential gene expression between resistant (R), susceptible $(\mathrm{S})$ and control $(\mathrm{C})$ groups, including fold change and $q$ value, which is analogous to an adjusted $p$ value or false discovery rate (FDR). Only genes with a fold change greater than 1.5 and $q$ value $\leq 0.05$ (FDR 5\%) were annotated.

\section{Molecular network and pathway analysis}

The Ingenuity Pathways Analysis (IPA) Spring Release (2013) Software (Qiagen) was used to identify networks of interacting genes and other functional groups from the datasets of differentially-expressed genes. DEG was analysed, by uploading the HUGO Gene Nomenclature Committee (HGNC) gene symbols for the sheep orthologues and fold change data to IPA.

\section{Results}

\section{Expression analysis by Affymetrix ovine gene array}

All microarray data, metadata and protocols are available in the ArrayExpress database under accession number E-MTAB-1580. The Affymetrix Ovine Gene 1.1 ST Arrays identified 43 genes (Table 1) in the ALN that showed significant difference (fold change $\geq 1.5$ and adjusted $p$ value $\leq 0.05$ ) in the $\mathrm{R}$ vs. $\mathrm{C}$ comparison, four genes in the $\mathrm{S}$ vs. $\mathrm{C}$ comparison and only three genes in the R vs. S comparison. All differentially-expressed genes in the $\mathrm{S}$ vs. $\mathrm{C}$ and $\mathrm{R}$ vs. $\mathrm{S}$ comparisons were also significantly differentially-expressed in the $\mathrm{R}$ vs. $\mathrm{C}$ comparison except VIRP2 that was 2.04 fold increased in susceptible sheep compared to controls.

Presentation of these data by heat map (Figure 1) illustrates that the overwhelming majority of the differentiallyexpressed genes are increased in the infected groups. Forty-one of the 43 genes in the $\mathrm{R}$ vs. $\mathrm{C}$ comparison are increased in the R group; all four of the genes in the $\mathrm{S}$ vs. $\mathrm{C}$ comparison were increased in the $\mathrm{S}$ group and all three in the $\mathrm{R}$ vs. $\mathrm{S}$ comparison were increased in the $\mathrm{R}$ group. IL13, COL6A5 and ACTG2 were significantly increased in the $\mathrm{R}$ animals when compared to both the $\mathrm{S}$ and $\mathrm{C}$ groups. 
Table 1 Differentially-expressed genes in ALN as assessed by Affymetrix ovine gene array.

\begin{tabular}{|c|c|c|c|c|c|c|c|c|}
\hline \multirow[b]{2}{*}{ Transcript } & \multirow[b]{2}{*}{ Accession number } & \multirow[b]{2}{*}{ Gene } & \multicolumn{2}{|l|}{ R vs.S } & \multicolumn{2}{|l|}{ R vs. C } & \multicolumn{2}{|l|}{ S vs. C } \\
\hline & & & $p$-value* & $\mathrm{FC}^{\S}$ & $p$-value* & FC & $p$-value* & FC \\
\hline 14836730 & NM_001082594 & IL13 & 7.44E-07 & 3.17 & $1.87 \mathrm{E}-08$ & 4.76 & 0.0195 & 1.50 \\
\hline 14863257 & XM_004003413 & COL6A5 & 8.64E-07 & 8.69 & $4.88 \mathrm{E}-07$ & 10.47 & 0.5421 & 1.21 \\
\hline 14722918 & XM_004005214 & CTNNAL1 & $2.52 \mathrm{E}-06$ & 1.45 & $4.03 \mathrm{E}-07$ & 1.56 & 0.2107 & 1.08 \\
\hline 14726591 & XM_004003604 & $\mathrm{CHI} 3 \mathrm{~L} 2$ & 0.1340 & -1.15 & $8.18 \mathrm{E}-06$ & 1.82 & $5.15 \mathrm{E}-07$ & 2.10 \\
\hline 14830831 & XM_004018378 & IL17RB & 0.0061 & 1.78 & $3.13 \mathrm{E}-07$ & 4.73 & $9.17 \mathrm{E}-05$ & 2.66 \\
\hline 14710165 & M84356 & IGHE & 0.4861 & 1.30 & $9.63 \mathrm{E}-07$ & 17.21 & $3.35 \mathrm{E}-06$ & 13.25 \\
\hline 14793854 & XM_004020976 & CCL26 & 3.37E-05 & 6.55 & $5.08 \mathrm{E}-07$ & 15.50 & 0.0252 & 2.37 \\
\hline 14806387 & XM_004006081 & ACTG2 & 2.09E-06 & 3.12 & $6.66 \mathrm{E}-06$ & 2.94 & 0.7353 & -1.06 \\
\hline 14795035 & XM_004018317 & IL5RA & 0.0031 & 1.64 & $6.59 \mathrm{E}-07$ & 3.15 & 0.0004 & 1.92 \\
\hline 14860591 & XM_004008559 & FCER2 & 0.3480 & -1.09 & $1.08 \mathrm{E}-05$ & 1.72 & $1.88 \mathrm{E}-06$ & 1.87 \\
\hline 14724715 & NM_001142892 & NFIL3 & 0.0241 & 1.21 & $1.76 \mathrm{E}-06$ & 1.77 & 0.0002 & 1.46 \\
\hline 14842210 & AC150860 & unknown & 0.0002 & 1.95 & $3.49 \mathrm{E}-06$ & 2.69 & 0.0422 & 1.38 \\
\hline 14731097 & XM_004021707 & PDLIM3 & 0.0420 & 1.19 & $3.46 \mathrm{E}-06$ & 1.74 & 0.0002 & 1.46 \\
\hline 14780240 & XM_004007330 & IL1RL1 & 0.0001 & 2.09 & $5.90 \mathrm{E}-06$ & 2.70 & 0.1112 & 1.29 \\
\hline 14763982 & XM_004015182 & FFAR2 & 0.0002 & 1.70 & $6.95 \mathrm{E}-06$ & 2.09 & 0.0921 & 1.23 \\
\hline 14894439 & NM_001009749 & SELE & 0.4637 & 1.09 & $4.34 \mathrm{E}-05$ & -1.88 & 1.03E-05 & -2.05 \\
\hline 14776999 & XR_083707 & EMR3 & 0.0006 & 4.02 & $6.48 \mathrm{E}-06$ & 9.29 & 0.0278 & 2.31 \\
\hline 14767454 & XM_004011302 & CD73 & 0.6156 & 1.04 & $1.76 \mathrm{E}-05$ & 1.65 & 4.74E-05 & 1.58 \\
\hline 14814624 & XM_004021547 & ANXA8 & 0.0470 & 1.47 & $7.46 \mathrm{E}-06$ & 3.25 & 0.0005 & 2.22 \\
\hline 14855554 & XM_004018137 & ASB2 & 0.1414 & 1.14 & $1.14 \mathrm{E}-05$ & 1.72 & 0.0002 & 1.51 \\
\hline 14826002 & XM_004012071 & CYSLTR2 & 0.0002 & 1.42 & $2.31 \mathrm{E}-05$ & 1.56 & 0.2324 & 1.10 \\
\hline 14826670 & XM_004003026 & APOD & 0.0074 & 1.75 & $1.19 \mathrm{E}-05$ & 3.21 & 0.0056 & 1.83 \\
\hline 14872046 & XM_004012573 & $\mathrm{P} 2 \mathrm{RX} 1$ & 9.97E-05 & 1.88 & $6.98 \mathrm{E}-05$ & 1.97 & 0.7164 & 1.05 \\
\hline 14724584 & XM_004022410 & IL13RA2 & 0.0019 & 2.34 & $1.92 \mathrm{E}-05$ & 4.10 & 0.0331 & 1.75 \\
\hline 14873273 & XM_004002636 & CD1A & 0.0455 & 1.31 & $1.92 \mathrm{E}-05$ & 2.15 & 0.0015 & 1.64 \\
\hline 14722365 & XM_004015563 & CCL17 & 0.5259 & 1.15 & $4.54 \mathrm{E}-05$ & 3.33 & 0.0002 & 2.90 \\
\hline 14766308 & XM_004002922 & CD200R1 & 0.0134 & 2.48 & $1.99 \mathrm{E}-05$ & 7.36 & 0.0054 & 2.97 \\
\hline 14789329 & XM_004004106 & SLC28A3 & 0.0006 & 2.33 & $3.76 \mathrm{E}-05$ & 3.15 & 0.1660 & 1.35 \\
\hline 14894373 & NM_001009251 & LGALS14 & 0.0166 & 2.44 & $2.72 \mathrm{E}-05$ & 7.25 & 0.0061 & 2.98 \\
\hline 14789001 & XM_004023684 & SMPD3 & 0.0002 & 2.17 & 0.0001 & 2.30 & 0.7191 & 1.06 \\
\hline 14854660 & XM_004018529 & $\mathrm{HRH} 1$ & 0.0032 & 1.31 & $3.40 \mathrm{E}-05$ & 1.57 & 0.0365 & 1.20 \\
\hline 14724104 & XR_173262 & ALOX15 & 0.0007 & 5.81 & $5.48 \mathrm{E}-05$ & 10.68 & 0.1877 & 1.84 \\
\hline 14768669 & XM_004013559 & SLC45A3 & 0.0003 & 1.50 & $9.12 \mathrm{E}-05$ & 1.61 & 0.4658 & 1.07 \\
\hline 14710170 & AF024645 & $\mathrm{IGHA}$ & 0.0023 & 1.55 & $4.03 \mathrm{E}-05$ & 2.01 & 0.0559 & 1.30 \\
\hline 14809379 & XM_004003929 & COL6A2 & 0.0059 & 1.43 & $3.89 \mathrm{E}-05$ & 1.93 & 0.0237 & 1.34 \\
\hline 14773724 & XM_004022514 & CRLF2 & 0.0015 & 1.66 & $9.79 \mathrm{E}-05$ & 2.03 & 0.1733 & 1.22 \\
\hline 14894389 & NM_001009425 & CD1B & 0.0031 & 1.54 & $9.02 \mathrm{E}-05$ & 1.94 & 0.0921 & 1.26 \\
\hline 14828762 & NM_181018 & CLCA3 & 0.0082 & 1.64 & $7.66 \mathrm{E}-05$ & 2.43 & 0.0346 & 1.48 \\
\hline 14713579 & AC225835 & CCL3L3 & 0.0391 & 1.23 & $7.62 \mathrm{E}-05$ & 1.65 & 0.0076 & 1.34 \\
\hline 14864484 & XM_004022897 & CD1B & 0.0091 & 1.39 & $9.87 \mathrm{E}-05$ & 1.79 & 0.0401 & 1.29 \\
\hline 14710851 & XM_004006654 & $\mathrm{NR} 1 \mathrm{H} 4$ & 0.0267 & 1.21 & 0.0001 & 1.51 & 0.0153 & 1.25 \\
\hline
\end{tabular}


Table 1 Differentially-expressed genes in ALN as assessed by Affymetrix ovine gene array. (Continued)

\begin{tabular}{lllllllll}
\hline 14891746 & XM_004012107 & TRPC4 & 0.0128 & 1.35 & $\mathbf{0 . 0 0 0 1}$ & $\mathbf{1 . 7 5}$ & 0.0324 & 1.30 \\
14784733 & XM_004015344 & CABP5 & 0.0183 & -1.25 & $\mathbf{0 . 0 0 0 1}$ & $\mathbf{- 1 . 5 6}$ & 0.0235 & -1.25 \\
14732131 & XM_004008376 & VIPR2 & 0.0420 & -1.28 & 0.0010 & 1.59 & $\mathbf{1 . 2 7 E - 0 5}$ & $\mathbf{2 . 0 4}$ \\
\hline
\end{tabular}

${ }^{*} P$ value with no FDR applied. ${ }^{5} \mathrm{FC}$; fold change. Bold; adjusted $p \leq 0.05$ after 5\% FDA.

CHI3L2, IGHE and FCER2 were significantly increased in both the $\mathrm{R}$ vs. $\mathrm{C}$ and $\mathrm{S}$ vs. $\mathrm{C}$ comparisons but not in the $\mathrm{R}$ vs. S comparison. VIPR2 was the only gene significantly increased in the $\mathrm{S}$ animals and not in the $\mathrm{R}$ group when compared to uninfected controls.

\section{RT-qPCR array validation}

Validation of the Affymetrix gene arrays was performed using the SABiosciences Cow Inflammatory Cytokines \& Receptors $\mathrm{RT}^{2}$ Profiler $^{\mathrm{Tw}}$ PCR Array which consists of 84 key genes that mediate inflammation. This assay is optimized for bovine genes and data were obtained for 83 genes when used with sheep cDNA (Additional file 1). The mean sequence identity between these 83 bovine and ovine genes is $96 \%$ (minimum 91\%, IL27; maximum 100\%, TNFSF13B). Single distinct melt curves obtained for all genes, except for $N A M P T$ (no data), in all samples confirmed the specificity of the assay. Furthermore, analysis of the sequences of ten sheep amplicons selected randomly (CCL11, CXCL13, IL2RB, IL2RG, IL4, IL6R, IL13, IL16, PF4, TNFSF4) and produced using the assay primers, showed them to be $100 \%$ identical to sequences of the respective sheep homologues.

Table 2 identifies those genes showing $\geq 1.5$ fold differential expression in the three comparisons. Three genes were significantly differentially expressed $(p \leq 0.05)$ in the $\mathrm{R}$ vs. C comparison, the Th2 cytokines IL4 and IL13 were increased by 11.9 and 3.96 fold respectively and MIP was repressed by 2.16 fold, in resistant sheep. IL4 (3.83 fold) and $I L 13$ (3.37 fold) were also significantly increased, and CCL5 (2.43 fold), CCL11 (2.11 fold), CXCR1 (2.49 fold), CXCR3 (2.25 fold) and TNFSF10 (2.03 fold) were significantly repressed in the susceptible animals when compared to uninfected controls. In the comparison of the two infected groups the Th2 cytokines IL5 (3.4 fold) and IL13 (3.54 fold) were significantly increased and the chemokine CCL5 (3.16 fold) was repressed in resistant sheep.

Spearman's rank correlation analysis of the fold changes calculated for all 83 genes in the R vs. C and S vs. C

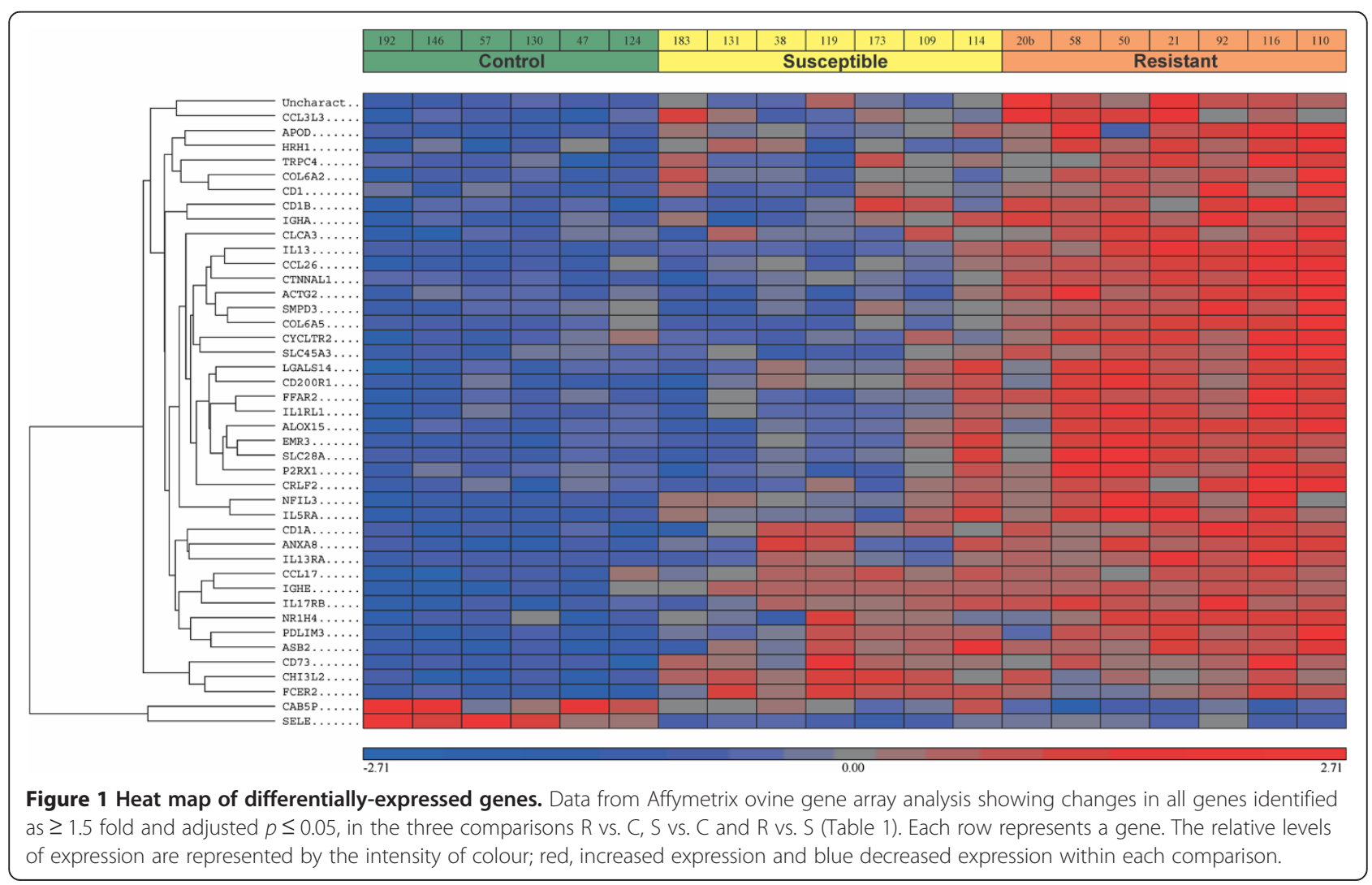


Table 2 Differential expression of inflammatory cytokines and receptors in ALN as assessed by RT-qPCR.

\begin{tabular}{|c|c|c|c|c|c|}
\hline $\begin{array}{l}\text { Up-regulated } \\
\text { genes }\end{array}$ & $\begin{array}{l}\text { Fold } \\
\text { change* }\end{array}$ & $p$-value & $\begin{array}{l}\text { Down-regulated } \\
\text { genes }\end{array}$ & $\begin{array}{l}\text { Fold } \\
\text { change }\end{array}$ & $p$-value \\
\hline \multicolumn{6}{|c|}{ Resistant vs. Control } \\
\hline IL4 & 3.96 & 0.006 & AIMP1 & -3.26 & 0.980 \\
\hline IL5 & 2.86 & 0.098 & BMP2 & -2.67 & 0.914 \\
\hline IL10RA & 2.43 & 0.063 & CCL20 & -2.57 & 0.119 \\
\hline IL13 & 11.92 & 0.001 & CXCL12 & -7.28 & 0.297 \\
\hline IL17B & 2.06 & 0.104 & IL2RB & -4.33 & 0.135 \\
\hline \multirow[t]{3}{*}{ IL9R } & 4.01 & 0.254 & MIF & -2.16 & 0.020 \\
\hline & & & TNFSF4 & -3.42 & 0.112 \\
\hline & & & VEGFA & -4.28 & 0.208 \\
\hline \multicolumn{6}{|c|}{ Susceptible vs. Control } \\
\hline IL4 & 3.83 & 0.007 & CCL5 & -2.43 & 0.008 \\
\hline \multirow[t]{9}{*}{ IL13 } & 3.37 & 0.030 & CCL11 & -2.11 & 0.046 \\
\hline & & & CXCL10 & -2.76 & 0.182 \\
\hline & & & CXCL12 & -2.24 & 0.263 \\
\hline & & & CXCL9 & -3.00 & 0.106 \\
\hline & & & CXCR1 & -2.49 & 0.006 \\
\hline & & & CXCR3 & -2.25 & 0.005 \\
\hline & & & IFNG & -2.14 & 0.135 \\
\hline & & & IL2RB & -4.71 & 0.100 \\
\hline & & & TNFSF10 & -2.03 & 0.020 \\
\hline \multicolumn{6}{|c|}{ Resistant vs. Susceptible } \\
\hline CCL5 & 3.16 & 0.030 & AIMP1 & -2.90 & 0.773 \\
\hline CCR2 & 2.58 & 0.185 & CXCL12 & -3.26 & 0.823 \\
\hline CXCL9 & 2.92 & 0.165 & TNFSF4 & -2.13 & 0.424 \\
\hline CXCL10 & 3.07 & 0.099 & VEGFA & -2.77 & 0.797 \\
\hline IFNG & 2.16 & 0.129 & & & \\
\hline IL5 & 3.40 & 0.045 & & & \\
\hline IL13 & 3.54 & 0.002 & & & \\
\hline IL17B & 2.71 & 0.061 & & & \\
\hline IL9R & 3.77 & 0.200 & & & \\
\hline
\end{tabular}

*Fold change is the ratio of normalized mean expression between resistant susceptible and control groups. Bold is $p \leq 0.05$.

comparisons (comparing 164 values) gave a low, but highly significant positive correlation $(\rho=0.37, P<0.0001)$ between the data obtained by the Affymetrix and PCR arrays. A direct comparison of quantitative expression of eight selected genes (Figure 2) shows the close relationship between the relative levels of expression measured by the two independent methods.

\section{Ingenuity pathway analysis}

IPA was used to help characterize how individual differentially-expressed genes interact, and consequently influence biological processes that affect the development of resistance or the maintenance of susceptibility to chronic T. circumcincta infection. Analysis of the data obtained using the Affymetrix gene array identified seven networks (Table 3), five with the $\mathrm{R}$ vs. $\mathrm{C}$ comparison and one each with the $\mathrm{S}$ vs. $\mathrm{C}$ and $\mathrm{R}$ vs. $\mathrm{S}$ comparisons. The top two ranked networks for the $\mathrm{R}$ vs. $\mathrm{C}$ dataset were Humoral Immune Response, Protein Synthesis, Inflammatory Response (Figure 3) and Hematological System Development and Function, with P-scores of 48 and 28 respectively. The three top Bio Functions, beyond the $p \leq 10^{-10}$ threshold, within these networks (Table 4a) were Immunological Disease with 24 genes with the highest $p$ value of $2.73 \times 10^{-13}$, Inflammatory Disease with 41 genes $p=8.34 \times 10^{-13}$, and Hypersensitivity Response with 19 genes $p=7.98 \times 10^{-11}$ associated with Diseases and Disorders and Hematological System Development and Function with 37 genes $p=4.79 \times 10^{-12}$, Tissue Morphology with 33 genes $p=4.79 \times 10^{-12}$, and Humoral Immune with 13 genes $p=2.28 \times 10^{-11}$, associated with Physiological System Development and Function.

The network Cell-To-Cell Signaling and Interaction, Hematological System Development and Function, Immune Cell Trafficking with a $P$ score of 24 was the only network identified for the $\mathrm{S}$ vs. $\mathrm{C}$ dataset (Table $4 \mathrm{~b}$ ); and Antigen Presentation, Lipid Metabolism, Small Molecule Biochemistry with a $P$ score of 18 was identified for the $\mathrm{R}$ vs. S comparison. Within these networks there were no Bio Functions beyond the $10^{-10}$ threshold (Table 4c).

The most significant network was Humoral Immune Response, Protein Synthesis, Inflammatory Response (R vs. C comparison), with IL13 as the central gene (Figure 2). IL13 was the top ranked gene in the $\mathrm{R}$ vs. $\mathrm{C}$ comparison, up-regulated 3.17 fold $\left(p=7.44 \times 10^{-7}\right)$ in resistant sheep. This was confirmed by the RT-qPCR analysis where it was 11.92 fold $(p=0.001)$ increased in the resistant group (Table 2). In this analysis it was also significantly upregulated in susceptible animals in the $\mathrm{S}$ vs. $\mathrm{C}$ comparison (3.37 fold $p=0.03$ ) and consequently 3.54 fold increased in resistant vs. susceptible sheep $(p=0.002)$.

\section{Mapping of sequencing tags to the sheep Oar v3.1 genome assembly}

A previous study [24] also performed transcriptome analysis on the abomasal lymph nodes of these resistant and susceptible sheep using Illumina digital gene expression analysis. These data were originally analysed in relation to the Bos taurus genome assembly (Btau4.0). Here, we reanalysed the same primary data (ArrayExpress E-MTAB-445) against the most recent Ovis aries genome assembly (Oar v3.1) to obtain more accurate gene mapping. The mean total number of reads of the samples from 15 sheep (5 resistant, 5 susceptible and 5 control) was 1 473000 , of which 288753 mapped to Btau4.0, with a maximum of 1 mismatch from an average tag length of 17 


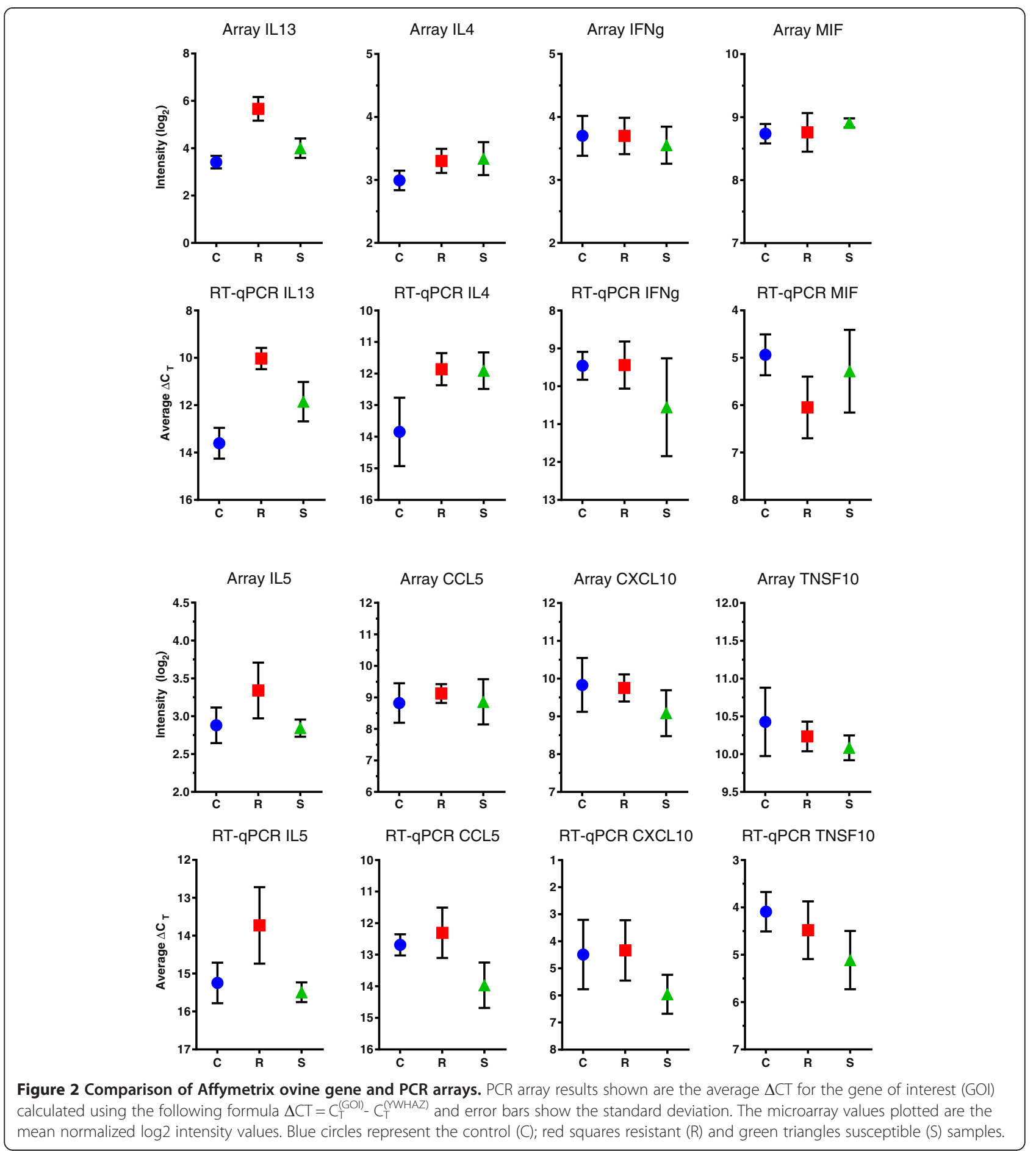

bases; in contrast 865844 tags mapped the Oar v3.1. A 2-4 fold increase in the number of significantly differentially expressed genes (Additional file 2) was also noted when comparing Oar v3.1 to Btau4.0; 229 in Oar v3.1 and 131 in Btau4.0 in the R vs. C comparison, 150 and 37 in the $\mathrm{S}$ vs. $\mathrm{C}$ comparison, and 146 and 83 in the $\mathrm{R}$ vs. $\mathrm{S}$ comparison.
IPA analysis of the revised digital gene expression data identified the top two networks (Additional file 3) in the R vs. C comparison as Cellular Growth and Proliferation, Cell Morphology, Cell-mediated Immune Response with a $P$-score of 56 and Post-Translational Modification, Hematological Disease, Cell Cycle, $P$-score of 52. The top network in the $\mathrm{S}$ vs. $\mathrm{C}$ comparison was Post-Translational 
Table 3 Top networks identified by ingenuity pathway analysis, from the Affymetrix ovine gene array.

\begin{tabular}{ll}
\hline Resistant vs. Control & Score \\
\hline Humoral Immune Response, Protein Synthesis, Inflammatory Response & 48 \\
Haematological System Development and Function, Haematopoiesis, Tissue Morphology & 28 \\
Cardiovascular System Development and Function, Cellular Movement, Gene Expression & 22 \\
Hereditary Disorder, Skeletal and Muscular Disorders, Tissue Morphology & 21 \\
Cell Signalling, Molecular Transport, Vitamin and Mineral Metabolism & 20
\end{tabular}

\section{Susceptible vs. Control}

Cell-To-Cell Signalling and Interaction, Haematological System Development and Function, Immune Cell Trafficking

Resistant vs. Susceptible

Antigen Presentation, Lipid Metabolism, Small Molecule Biochemistry

Modification, Cell Signaling, DNA Replication, Recombination, and Repair with a P-score of 54. The top Bio Functions (Additional file 4) within these networks include Cancer, Gastrointestinal Disease, Dermatological Disease and Conditions and Immunological Disease; however, none of these Bio Functions reached the $p \leq 10^{-10}$ threshold.

\section{Discussion}

This project is the logical extension of our three previous studies [24,32,33] concerned with the genetics and immunology of resistant and susceptible Blackface sheep persistently infected with the common abomasal nematode parasite, T. circumcincta. The first [32] described hostparasite interactions in a single intensively-phenotyped cohort with variable susceptibility; which were exploited to help analyse the nature of the mature host response associated with differential resistance [24,33]; although this misses early events associated with the development of immune responses The aim of the current study was to identify genes and physiological pathways associated with the differential activation of the immune response, linked

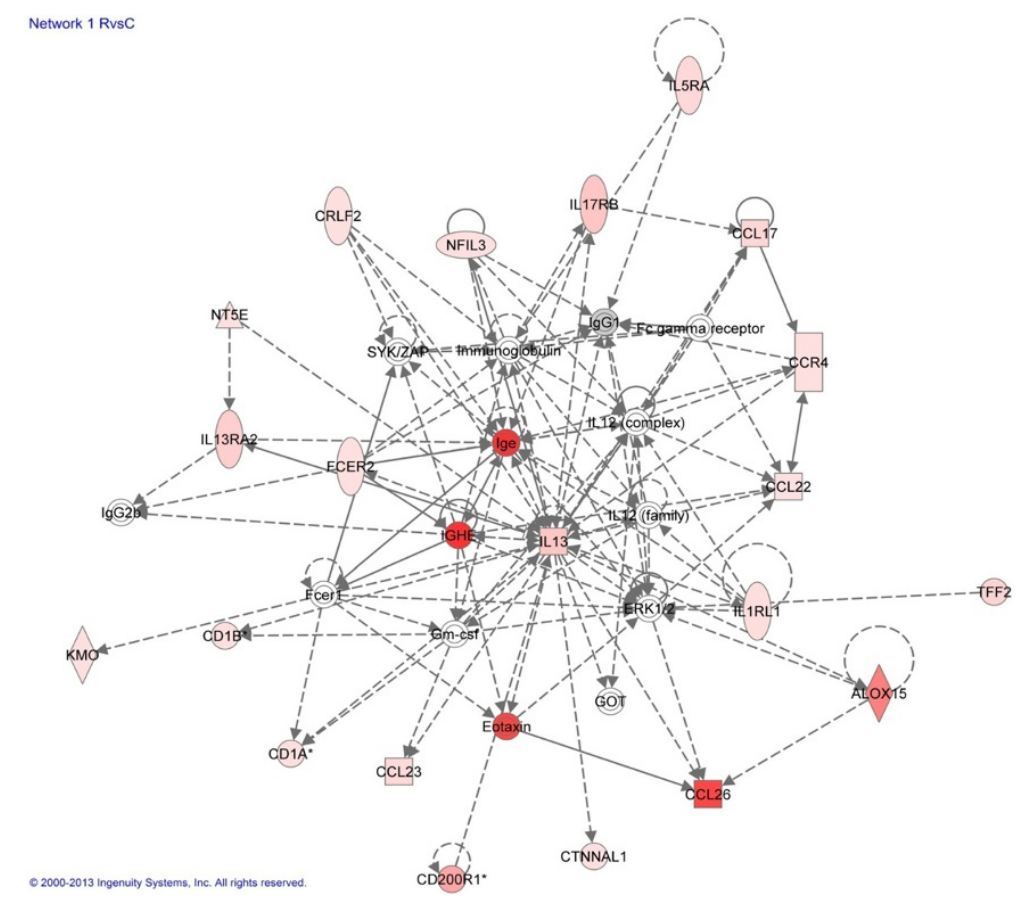

Figure 3 Ingenuity pathway analysis of the top-ranked network. The top- ranked network is "Humoral Immune Response, Protein Synthesis, Inflammatory Response" with a P-score of 48 based on Ingenuity Pathway Knowledge Base. Analysis used differentially-expressed genes from the Affymetrix Gene Array with $\geq 1.5$ fold change, $p$-values of $\leq 0.05$ and a FDR of 0.15 . The shape of the nodes indicates the major function of the protein expressed by that gene. Red coloured nodes (genes) are up-regulated and the density relates to expression levels. Uncoloured nodes represent genes not identified as differentially-expressed in the current study. A solid line indicates direct evident and a dashed line indirect evidence of interaction. The arrow head show the direction of interaction. 
Table 4 Top bio functions identified by ingenuity pathway analysis, from the Affymetrix ovine gene array.

$$
\text { a. } \mathrm{R} \text { vs. } \mathrm{C} \text { comparison }
$$

\begin{tabular}{lc}
\hline DISEASES AND DISORDERS & $P$-value
\end{tabular}

Immunological Disease

CSF3R, SELE, PTGDR2, IL1RL1, IGHE, VIPR2, CCL23, NR1H4, IL13RA2, CCL17, CCL22, IL13, ADRA1D, HRH1, IL17RB, CCR4, CCL2, NLRP12, CD1A, CCL26, CFH,HRH4, CYSLTR2, FCER2.

$$
\begin{aligned}
& 2.73 \times 10^{-13}-6.71 \times 10^{-03} \\
& 8.34 \times 10^{-13}-6.71 \times 10^{-03}
\end{aligned}
$$

GATA1, CRLF2, NR1H4, VIPR2, IL1RL1, IL13RA2, SOCS2, P2RX1, CCL17, SLC9A4, CCL22, HRH1, NFIL, TFF2, CCL2, CD1A, HPGD, CFH, CYSLTR2, FCER2, CSF3R, ALOX15, SELE, PTGDR2, IL5RA, CCL23, IGHE, CD200R1, CD1B, ULBP1, P2RX7, IL13, IL17RB, CCR4, NT5E, NLRP12, PILRA, CCL26, IGHA1, SH2D1B, HRH4.

\section{Hypersensitivity Response}

ALOX15, PTGDR2, SELE, IL5RA, GATA1, VIPR2, IL1RL1, IGHE, CD200R1, CCL17, CCL22,

P2RX7, IL13, IL17RB, CCR4, CCL2, CCL26, HRH4, FCER2

\section{Dermatological Diseases and Conditions}

ALOX15, PTGDR2, SELE, IGHE, VIPR2, NR1H4, CCL23, CCL17, CCL22, IL13, ADRA1D, HRH1, IL17RB, CCL2, CCR4, NT5E, CD1A, HPGD, HRH4, CYSLTR2, FCER2

\section{Inflammatory Disease}

CRLF2, NR1H4, IL1RL1, VIPR2, IL13RA2, CCL17, CCL22, HRH1, TH, COL6A1, CCL2, CD1A, HPGD, CFH, CYSLTR2, FCER2, CSF3R, ALOX15, SELE, PTGDR2, IL5RA, CCL23, IGHE, CD200R1, P2RX7, IL13, ADRA1D, GLIPR2, IL17RB, CCR4, NT5E, NLRP12, CCL26.

\section{PHYSIOLOGICAL SYSTEM DEVELOPMENT AND FUNCTION}

\section{Haematological System Development and Function}

GATA1, CRLF2, VIPR2, IL1RL1, SOCS2, IL13RA2, P2RX1, CCL17, CCL22, HRH1, NFIL3, TFF2, CCL2, CD1A, CFH, CYSLTR2, FCER2, CSF3R, ALOX15, PTGDR2, SELE, IL5RA, IGHE, CCL23, CD200R1, CD1B, ULBP1, P2RX7, IL13, ZBTB32, IL17RB, CCR4, NLRP12, NT5E, MYOCD, CCL26, CYP4A11.

\section{Tissue Morphology}

GATA1, CRLF2, VIPR2, IL1RL1, NR1H4, IL13RA2, SLC9A4, CCL22, TH, HRH1, NFIL3,TFF2, CCL2, CFH, SMPD3, FCER2, CSF3R, ALOX15, SELE, PTGDR2, IL5RA, IGHE, CD200R1, P2RX, IL13, OXT, IL17RB, CCR4, NLRP12, NT5E, FLNC, CNN1, CYP4A11.

\section{Humoral Immune Response}

HRH1,PTGDR2, NFIL3, IL5RA, IL17RB, CRLF2, CCR4, IGHE, IL1RL1, IL13RA2, IL13, HRH4, FCER2.

\section{Immune Cell Trafficking}

IL1RL1, VIPR2, SOCS2, CCL17, CCL22, HRH1, NFIL3, TFF2, CCL2, CD1A, CFH

CYSLTR2, FCER2, CSF3R, ALOX15, PTGDR2, SELE, IGHE, CCL23, CD200R1,

ULBP1, CD1B, P2RX7, IL13, IL17RB, CCR4, NT5E, NLRP12, CCL26.

\section{Cell-mediated Immune Response}

PTGDR2, SELE, GATA1, CCR4, CCL2, IL1RL1, CCL23, IL13RA2, CCL17, CCL22, IL13.

$7.98 \times 10^{-11}-4.94 \times 10^{-03}$

$1.78 \times 10^{-09}-6.71 \times 10^{-03}$

$1.78 \times 10^{-09}-5.7 \times 10^{-03}$

$P$-value

$4.79 \times 10^{-12}-6.71 \times 10^{-03}$

$4.79 \times 10^{-12}-6.49 \times 10^{-03}$

$2.28 \times 10^{-11}-6.53 \times 10^{-03}$

$5.04 \times 10^{-10}-6.71 \times 10^{-03}$

Lymphoid Tissue Structure and Development

CSF3R, ALOX15, SELE, GATA1, CRLF2, IL1RL1, IL13RA2, CCL17, CCL22,

P2RX7, L13, CCL2, CCR4, NT5E, CYSLTR2

Digestive System Development and Function

TFF2, NR1H4, IL13RA2, SLC9A4, IL13

$2.41 \times 10^{-05}-4.94 \times 10^{-03}$

DISEASES AND DISORDERS

b. S vs. C comparison

Hypersensitivity Response

FCER2, IGHE, SELE, VIPR2.

$1.09 \times 10^{-08}-5.63 \times 10^{-03}$

$3.82 \times 10^{-07}-5.7 \times 10^{-03}$

Inflammatory Disease

FCER2, IGHE, IGKC, NT5E, SELE, VIPR2

PHYSIOLOGICAL SYSTEM DEVELOPMENT AND FUNCTION

Hematological System Development and Function

FCER2, IGHE, IGKC, SELE, NT5E, VIPR2.
$4.64 \times 10^{-05}-4.10 \times 10^{-02}$

\section{$P$-value}

$1.76 \times 10^{-06}-3.31 \times 10^{-02}$

$P$-value

$1.76 \times 10^{-06}-4.57 \times 10^{-02}$ 
Table 4 Top bio functions identified by ingenuity pathway analysis, from the Affymetrix ovine gene array. (Continued)

\begin{tabular}{lr}
\hline Immune Cell Trafficking & \\
\hline \multicolumn{1}{c}{ C. R vs. S comparison } & $1.76 \times 10^{-06}-4.57 \times 10^{-02}$ \\
\hline DISEASES AND DISORDERS & $P$-value \\
Gastrointestinal Disease & $9.85 \times 10^{-06}-2.62 \times 10^{-02}$ \\
CCL26, IL13. & \\
Hematological Disease & $9.85 \times 10^{-06}-2.62 \times 10^{-02}$ \\
CCL26, CD1A, IL13, FCER2, IGHE, IGKC, NT5E, SELE, VIPR2. & P-value \\
PHYSIOLOGICAL SYSTEM DEVELOPMENT AND FUNCTION & \\
Hematological System Development and Function & $2.35 \times 10^{-05}-4.76 \times 10^{-02}$ \\
CCL26, CD1A, IL13. & \\
Immune Cell Trafficking & $2.35 \times 10^{-05}-4.76 \times 10^{-02}$ \\
CCL26, CD1A, IL13. & \\
\hline
\end{tabular}

to the maintenance of resistance and susceptibility. It is part of a larger project that eventually aims to identify candidate genes that could be used as selectable markers of resistance in these Blackface sheep as well as other commercial sheep breeds.

The study exploits a new genomics resource for the analysis of the sheep transcriptome; the homologous Affymetrix Gene 1.1 ST Array based on the Ovis aries Oar v2 genome assembly. This consists of 508 538, 25mer probes for 22047 genes, which interrogate approximately 625 bases per gene covering all exons of each transcript. Also new to this study is the use and validation of the SABiosciences Cow Inflammatory Cytokines \& Receptors $\mathrm{RT}^{2}$ Profiler $^{\mathrm{TM}}$ PCR Array in sheep; enabling 83 RT-qPCR assays to be used to validate the arrays rather than the more usual 8 or 10 genes. In addition we reanalysed first generation Illumina digital gene expression data [24] using the latest sheep genome assembly (Oar v3.1) with significantly different results; more than 3 times the number of tags mapped to Oar v3.1 as originally mapped to Btau 4.0. The only other study [40] that has examined the sheep ALN transcriptome used a small array of 1480 annotated probes with 5373 unannotated expressed sequence tags. This identified only one differentially expressed gene (HSPA1A) in relation to $H$. contortus infection.

The sheep in this study that were predicted to show variation in resistance to $T$. circumcincta were trickleinfected regularly for 3 months to mimic natural infection and continual exposure. They were analysed when the mature immune response of the resistant animals had controlled and/or eliminated that infection. At the same time susceptible animals did not control infection, and retained adult nematodes that produced large numbers of eggs [32]. A previous study showed that these susceptible sheep generated an active Th17 immune and inflammatory response that failed to control infection [33]. In this current study the results of the array analysis focused on the nature of the mature host response in the resistant animals, which controls nematode colonization despite chronic exposure to infectious larvae.

Murine models of nematode parasite immunity, resistance and susceptibility, using the nematodes Heligmosomoides polygyrus, Nippostrongylus brasiliensis and Trichuris muris are linked to strong Th2 responses, indicated by high levels of the cytokines interleukin 4 (IL4) and IL13 with parasite immunity and resistance, and high levels of interferon $\gamma($ IFN $\gamma$ ) with susceptibility [41-43]. It is clear from the IPA in this study that the host response linked to parasite control is strongly associated with the network "Humoral Immune Response, Protein Synthesis, Inflammatory Response" and that many of the network genes are key regulators of a Th2 cell response and are strongly up-regulated in the resistant sheep. This is in agreement with the results from the array analysis of the mucosa from challenge-treatedreinfected "immune" sheep [29]. IL4 and IL13 are the two cytokines that principally control Th2 differentiation $[44,45]$; both were significantly increased in resistant sheep, IL4 (3.96 fold in R vs. C) in the RT-qPCR and IL13 in both array (4.76 fold in R vs. C and 3.17 fold in R vs. S) and RT-qPCR (11.92 fold in R vs. C and 3.54 in $\mathrm{S}$ vs. C). These cytokines have related receptors and IL13RA2 is also up-regulated in resistant sheep; binding to their cognate receptors stimulates the activation of STAT6 that controls the expression of GATA3, the prime transcription factor for Th2 differentiation [46]. IL5 is the third archetypal Th2 cytokine, and is also increased in resistant sheep (3.4 fold in R vs. S by RTqPCR). A major function of IL5 is in stimulating eosinophil maturation and localization; these are crucial 
effector cells in the exclusion of $T$. circumcincta through binding to parasite-specific IgG, IgE and IgA antibodies and subsequent degranulation [13]. Eosinophils are most numerous in the mucosa of the resistant sheep [47] evidenced by the increased expression, by array, of both FCER2 (1.72 fold in R vs. S) the low affinity receptor of IgE, and the IL5 receptor (IL5RA 3.15 fold in R vs. C) both expressed by eosinophils (Table 1 ).

Sheep control larval colonization, worm development and egg production through the generation of parasitespecific IgA and IgE antibodies [7,9,11,20]. Levels of these two antibody classes are highly negatively correlated with worm length and fecundity and FEC [32] and both IgA (IGHA 2.01 fold) and IgE (IGHE 17.21 fold) are significantly increased (both by array) in the resistant sheep. The generation of Th2 responses in the gastrointestinal tract seem to be induced by the events at the mucosal epithelial surface [48]. The intestinal epithelium is activated by parasite antigens via innate receptors and secrete the cytokines IL25 and IL33 that act on the newly identified innate lymphoid cells (ILC2) [49], and TSLP that acts on dendritic cells (DC) [50]. This leads to IL13 expression by ILC2 and Th2 activation by the DCs. Major parts of the receptors for these cytokines are up-regulated (by array) in resistant sheep; IL17RB (receptor for IL25) is increased 4.73 fold, IL1RL1 (IL33 receptor and the principal marker for ILC2) in increased 2.7 fold and CRLF2 (TSLP receptor) is increased 2.03 fold, in the R vs. C comparison. The endothelia and DCs in the abomasal lymph nodes of resistant sheep express significantly increased levels of HRH1 (1.57 in R vs. C). Histamine receptor positive DCs modulate Th1/Th2 balance by inhibiting IL12R1 signalling thus promoting Th2 responses [51].

However, resistance and susceptibility is not just a matter of Th1/Th2 discrimination as susceptible sheep also show increased expression of IL4 (3.83 fold in S vs. C) and IL13 (3.37 fold in S vs. C) by RT-qPCR and IGHE (13.25 fold in $\mathrm{S}$ vs. C) by array. IGHA is only marginally increased (but non-significant) in these susceptible animals. Nevertheless the mature tissue response of the resistant and susceptible sheep is distinct [33]. The abomasal mucosa of resistant sheep, at least 6 weeks after the last positive FEC, has evidence of only minor pathological change with small numbers of infiltrating lymphocytes and eosinophils. In contrast the mucosa of susceptible sheep was grossly inflamed.

These pathological differences are reflected in the differential expression of the chemokines, molecules which control leukocyte movement. The high expression of CCL17 (3.33 fold in R vs. C in array) and CCL26 or eotaxin-3 (15.5 fold in R vs. $\mathrm{C}$ in array) begins to explain the nature of mucosal infiltrate of resistant sheep, which consists largely of lymphocytes and eosinophils [52,53].
Indeed CCL17 is chemotactic for, and activates, CCR4+ Th2 cells; their expression of IL4 and IL13 stimulates the expression of CCL26, which is chemotactic for eosinophils and basophils. IL13 also stimulates the expression of CCL5 (CCL5 3.15 fold in R vs. C in RT-qPCR) by activated $\mathrm{T}$ and NK cells, which is chemotactic for memory T cells and promotes Th2 responses [54].

Changes to these and many of the other genes indicate that a principal component of the response of resistant animals also includes a repression of acute inflammation and tissue healing. The low levels of MIF (-2.16 in R vs. $\mathrm{C}$ in array) and SELE ( -1.8 in $\mathrm{R}$ vs. $\mathrm{C}$ in array) begins to explain the paucity of neutrophils in resistant animals [55]. A principal function of MIF is induction of proinflammatory cytokines, which stimulates SELE (Eselectin) expression and hence neutrophil localization [56]; however the level of SELE in resistant sheep is significantly repressed, possibly explaining the lack of neutrophils in the abomasal mucosa of these animals [33]. Three other genes which play significant roles in the regulation of inflammation are increased in resistant sheep. ALOX15 (lipoxygenase 15) is induced by IL4 and IL13 and inhibits pro-inflammatory leukotrienes and suppresses neutrophil chemotaxis; NR1H4 plays an key role in cholesterol homeostasis and inhibits IL1 $\beta$ induced inflammation [57]; CD200R is the Ox-2 receptor expressed on myeloid cells and functions to downregulate myeloid cell activation and therefore depress inflammation [58]. Both resistant and susceptible sheep are equally affected for the first 6 weeks of trickle infection [32] but only resistant animals control infection. Consequently the abomasum of those animals begins to heal; and this is seen by the significant changes ( $\mathrm{R}$ vs. S and $\mathrm{R}$ vs. $\mathrm{C}$ ) to genes associated with healing, with an 8 - 10 fold increase in type VI collagen (COL6A5) and a 3 fold increase in enteric smooth muscle actin (ACTG2).

VIPR2 (2.04 in S vs. C) is the one gene in the array that is differentially-expressed in susceptible sheep but not in the resistant group. This is the vasoactive intestinal peptide receptor; ligand-receptor interactions leads to inhibition of IL2-driven $\mathrm{T}$ cell proliferation and chemoattraction [59], consistent with the immunopathology of the susceptible abomasum. The excretory/ secretory antigens of $T$. circumcincta have been shown to induce the expression of FoxP3 by murine $\mathrm{T}$ cells in vitro [60]; however there is no evidence for any increase in Tregs in the parasite-free resistant or highlyinfected susceptible sheep.

The ultimate aim of these studies was to identify candidate genes as potential selectable markers for resistance to $T$. circumcincta infection. Within this study we have highlighted a small number of physiological pathways associated with differential susceptibility in Blackface sheep; in particular identified genes linked to 
differential $\mathrm{T}$ cell polarization. The Affymetrix ovine gene array incorporates probes for all the annotated exons within the sheep genome and a major advantage of using this technology is that differential transcript usage can be identified directly. We are currently analysing the array data to identify transcript variants of genes within the top-networks that are differentially-expressed in relation to resistance and susceptibility.

\section{Additional files}

\section{Additional file 1: Digital gene expression analysis of gastric lymph node of $T$. circumcincta infected sheep. Differentially expressed genes in the R vs. C, S vs. C and R vs. S comparisons analysed using the Ovis aries Oar v3.1 genome assembly. Mean; $\Delta \Delta \mathrm{Ct}$ (mean $\mathrm{Ct}^{\mathrm{GOI}}$ - meanC ${ }^{\text {YWHAZ}}$ ). \\ Additional file 2: RT-qPCR analysis of gastric lymph node of $T$. circumcincta infected sheep. Differentially expressed genes in the R vs. C and S vs. C comparisons. Mean R, S, C; mean tag numbers per $10^{6}$ tags in Resistant (R), Susceptible (S), Control (C). FC R/C, S/C, R/S; fold change Resistant vs. Control (R/C), Susceptible vs. Control (S/C, Resistant vs. Susceptible (R/S).}

Additional file 3: Top networks identified by Ingenuity Pathway Analysis, from the Illumina digital gene expression data. Network $P$-scores $[-\log 10(P$-value $)]$ is the probability of a network being randomly generated.

Additional file 4: Top Bio Functions identified by Ingenuity Pathway Analysis, from Illumina digital gene expression data. $P$-values calculated by Fisher's exact test.

\section{Competing interests}

The authors declare that they have no competing interests.

\section{Authors' contributions}

$\mathrm{JH}$ conceived the study, collected the samples and is the principal investigator. AGG and JH designed the current experiments; AGG performed the Affymetrix and RT-qPCR experiments and was responsible for the statistical, bioinformatic and pathway analysis. DB performed the original digital gene expression study, including the bioinformatics. HW and AJ reanalyzed the digital gene expression in relation to Oar v3.1. JH drafted the manuscript. All the authors have read and approved the final manuscript.

\section{Acknowledgements}

This project was funded initially by the Natural Environment Research Council (NERC) through its "Post-Genomics and Proteomics" programme (grant NE/D000645/1) and subsequently by the Biotechnology and Biological Sciences Research Council (BBSRC) Institute Strategic Programme Grant to The Roslin Institute. HW is a BBSRC Industrial CASE scholar, sponsored by Sheep Improved Genetics Ltd and Eblex (grant BB/J012653/1). AJ acknowledges funding from the 3SR project (Sustainable Solutions for Small Ruminants) $-7^{\text {th }}$ Framework Programme, call identifier FP7-KBBE-2009-3, Project 245140. We thank Professor Josephine Pemberton (Institute of Evolutionary Biology, University of Edinburgh) and Dr Dario Beraldi (CRUK, L Ka Shing Centre, Cambridge) for original collaboration on the larger project and critical appraisal of the manuscript; Joan Docherty (The Marshall Building) for animal husbandry and collection of weight data and blood samples; Barbara Craig for the original parasitological measurements; staff at Genepool and ARKGenomics for help with the RNAseq and Affymetrix respectively.

Received: 21 May 2013 Accepted: 2 August 2013 Published: 8 August 2013

\section{References}

1. Brunsdon RV: The economic impact of nematode infection in sheep: implications for future research and control. In The economic importance of parasites of livestock in New Zealand. Edited by Heath ACG. New Zealand: New Zealand Society for Parasitology; 1988:4-16
2. Urquhart GM, Armour J, Duncan JL, Dunn AM, Jennings FW: Veterinary Parasitology. Avon: Longman Scientific and Technical; 1987.

3. Coles GC, Jackson F, Pomroy WE, Prichard RK, von-Samson-Himmelstjerna G, Silvestre A, Taylor MA, Vercruysse J: The detection of anthelmintic resistance in nematodes of veterinary importance. Vet Parasitol 2006, 136:167-185.

4. Sargison ND, Scott PR, Wilson DJ, Macrae Al, Penny CD: Teladorsagia circumcincta resistance to moxidectin and multiple anthelmintic groups in ewes following use of the persistent drug before lambing. Vet Rec 2010, 167:523-527.

5. Cooper K, Whyte M, Danaher M, Kennedy D: Emergency slaughter of casualty cattle increases the prevalence of anthelmintic drug residues in muscle. Food Addit Contam Part A Chem Anal Control Expo Risk Assess 2012, 29:1263-1271.

6. Eady SJ, Woolaston RR, Barger IA: Comparison of genetic and nongenetic strategies for control of gastrointestinal nematodes of sheep. Livest Prod Sci 2003, 81:11-23.

7. Stear MJ, Strain S, Bishop SC: Mechanisms underlying resistance to nematode infection. Int J Parasitol 1999, 29:51-56.

8. Stear MJ, Strain S, Bishop SC: How lambs control infection with Ostertagia circumcincta. Vet Immunol Immunopathol 1999, 72:213-218.

9. Smith WD, Jackson F, Jackson E, Graham R, Williams J, Willadsen SM, Fehilly CB: Transfer of immunity to Ostertagia circumcincta and IgA memory between identical sheep by lymphocytes collected from gastric lymph. Res Vet Sci 1986, 41:300-306.

10. Halliday AM, MCAllister HC, Smith WD: Kinetics of the local immune response in the gastric lymph of lambs after primary and challenge infection with Teladorsagia circumcincta. Parasite Immunol 2010, 32:81-90.

11. Murphy L, Eckersall PD, Bishop SC, Pettit JJ, Huntley JF, Burchmore R, Stear MJ: Genetic variation among lambs in peripheral IgE activity against the larval stages of Teladorsagia circumcincta. Parasitology 2010, 137:1249-1260.

12. Huntley JF: Mast cells and basophils: a review of their heterogeneity and function. J Comp Pathol 1992, 107:349-372

13. Henderson NG, Stear MJ: Eosinophil and IgA responses in sheep infected with Teladorsagia circumcincta. Vet Immunol Immunopathol 2006, 112:62-66.

14. Stear MJ, Bishop SC, Doligalska M, Duncan JL, Holmes PH, Irvine J, McCririe L, McKellar QA, Sinski E, Murray M: Regulation of egg production, worm burden, worm length and worm fecundity by host responses in sheep infected with Ostertagia circumcincta. Parasite Immunol 1995, 17:643-652.

15. Shaw R, Morris C, Wheeler M, Tate M, Sutherland I: Salivary IgA: a suitable measure of immunity to gastrointestinal nematodes in sheep. Vet Parasitol 2012, 186:109-117.

16. Sayers $G$, Sweeney T: Gastrointestinal nematode infection in sheep-a review of the alternatives to anthelmintics in parasite control. Anim Health Res Rev 2005, 6:159-171.

17. Mugambi J, Bain R, Wanyangu S, Ihiga M, Duncan J, Murray M, Stear M: Resistance of four sheep breeds to natural and subsequent artificial Haemonchus contortus infection. Vet Parasitol 1997, 69:265-273.

18. Terefe G, Lacroux C, Andreoletti O, Grisez C, Prevot F, Bergeaud JP, Penicaud J, Rouillon V, Gruner L, Brunel JC, Francois D, Bouix J, Dorchies P, Jacquiet P: Immune response to Haemonchus contortus infection in susceptible (INRA 401) and resistant (Barbados Black Belly) breeds of lambs. Parasite Immunol 2007, 29:415-424

19. Sayers G, Good B, Hanrahan JP, O'Donovan J, Mulcahy G, Sweeney T: Breed differences in mucosal and systemic antibody response to nematode infection in sheep: an important role for lgE? Parasitology 2008, 135:71-80.

20. Gasbarre LC, Leighton EA, Sonstegard T: Role of the bovine immune system and genome in resistance to gastrointestinal nematodes. Vet Parasitol 2001, 98:51-64.

21. Dominik S: Quantitative trait loci for internal nematode resistance in sheep: a review. Genet Sel Evol 2005, 37(Suppl 1):S83-S96.

22. Stear MJ, Abuagob O, Benothman M, Bishop SC, Innocent G, Kerr A, Mitchell S: Variation among faecal egg counts following natural nematode infection in Scottish Blackface lambs. Parasitology 2006, 132:275-280.

23. Davies G, Stear MJ, Benothman M, Abuagob O, Kerr A, Mitchell S, Bishop SC. Quantitative trait loci associated with parasitic infection in Scottish blackface sheep. Heredity 2006, 96:252-258.

24. Pemberton JM, Beraldi D, Craig BH, Hopkins J: Digital gene expression analysis of gastrointestinal helminth resistance in Scottish blackface lambs. Mol Ecol 2011, 20:910-919. 
25. Slate J, Gratten J, Beraldi D, Stapley J, Hale M, Pemberton JM: Gene mapping in the wild with SNPs: guidelines and future directions. Genetica 2009, 136:97-107

26. Brown EA, Pilkington JG, Nussey DH, Watt KA, Hayward AD, Tucker R, Graham AL, Paterson S, Beraldi D, Pemberton JM, Slate J: Detecting genes for variation in parasite burden and immunological traits in a wild population: testing the candidate gene approach. Mol Ecol 2013, 22:757-773.

27. Diez-Tascon C, Keane OM, Wilson T, Zadissa A, Hyndman DL, Baird DB, McEwan JC, Crawford AM: Microarray analysis of selection lines from outbred populations to identify genes involved with nematode parasite resistance in sheep. Physiol Genomics 2005, 21:59-69.

28. Rowe A, Gondro C, Emery D, Sangster N: Genomic analyses of Haemonchus contortus infection in sheep: abomasal fistulation and two Haemonchus strains do not substantially confound host gene expression in microarrays. Vet Parasitol 2008, 154:71-81

29. Knight PA, Griffith SE, Pemberton AD, Pate JM, Guarneri L, Anderson K, Talbot RT, Smith S, Waddington D, Fell M, Archibald AL, Burgess ST, Smith DW, Miller HR, Morrison IW: Novel gene expression responses in the ovine abomasal mucosa to infection with the gastric nematode Teladorsagia circumcincta. Vet Res 2011, 42:78.

30. Knight JS, Baird DB, Hein WR, Pernthaner A: The gastrointestinal nematode Trichostrongylus colubriformis down-regulates immune gene expression in migratory cells in afferent lymph. BMC Immunol 2010, 11:51.

31. Ingham A, Reverter A, Windon R, Hunt P, Menzies M: Gastrointestinal nematode challenge induces some conserved gene expression changes in the gut mucosa of genetically resistant sheep. Int J Parasitol 2008 38:431-442.

32. Beraldi D, Craig BH, Bishop SC, Hopkins J, Pemberton JM: Phenotypic analysis of host-parasite interactions in lambs infected with Teladorsagia circumcincta. Int J Parasitol 2008, 38:1567-1577.

33. Gossner AG, Venturina VM, Shaw DJ, Pemberton JM, Hopkins J: Relationship between susceptibility of Blackface sheep to Teladorsagia circumcincta infection and an inflammatory mucosal T cell response. Vet Res 2012, 43:26.

34. Benjamini $Y$, Hochberg $Y$ : Controlling the false discovery rate: a practical and powerful approach to multiple testing. J R Statist Soc B 1995, 57:289-300

35. ArrayExpress database; 2013 [http://www.ebi.ac.uk/arrayexpress/]

36. Sheep genome assembly Oar v3.1.; 2013 [http://www.livestockgenomics. csiro.au/cgi-bin/gbrowse/oarv3.1/]

37. Langmead B, Trapnell C, Pop M, Salzberg SL: Ultrafast and memoryefficient alignment of short DNA sequences to the human genome. Genome Biol 2009, 10:R25.

38. Smyth GK: Limma: linear models for microarray data. In Bioinformatics and computational biology solutions using $R$ and bioconductor. Edited by Gentleman R, Carey V, Dudoit S, Irizarry R, Huber W. New York: Springer; 2005:397-420

39. Gentleman RC, Carey VJ, Bates DM, Bolstad B, Dettling M, Dudoit S, Ellis B, Gautier L, Ge Y, Gentry J, Hornik K, Hothorn T, Huber W, lacus S, Irizarry R, Leisch F, Li C, Maechler M, Rossini AJ, Sawitzki G, Smith C, Smyth G, Tierney $L$, Yang JY, Zhang J: Bioconductor: open software development for computational biology and bioinformatics. Genome Biol 2004, 5:R80.

40. Andronicos N, Hunt P, Windon R: Expression of genes in gastrointestinal and lymphatic tissues during parasite infection in sheep genetically resistant or susceptible to Trichostrongylus colubriformis and Haemonchus contortus. Int J Parasitol 2010, 40:417-429.

41. Maizels RM, Yazdanbakhsh M: Immune regulation by helminth parasites: cellular and molecular mechanisms. Nat Rev Immunol 2003, 3:733-744.

42. Cliffe $L$, Grencis RK: The Trichuris muris system: a paradigm of resistance and susceptibility to intestinal nematode infection. Adv Parasitol 2004 57:255-307.

43. Anthony RM, Rutitzky LI, Urban JF, Stadecker MJ, Gause WC: Protective immune mechanisms in helminth infection. Nat Rev Immunol 2007, 7:975-987.

44. Finkelman FD, Shea-Donohue T, Morris SC, Gildea L, Strait R, Madden KB, Schopf L, Urban JF: Interleukin-4- and interleukin-13-mediated host protection against intestinal nematode parasites. Immunol Rev 2004 201:139-155.

45. Wynn TA: IL-13 effector functions. Annu Rev Immunol 2003, 21:425-456.
46. Ho IC, Tai TS, Pai SY: GATA3 and the T-cell lineage: essential functions before and after T-helper-2-cell differentiation. Nat Rev Immunol 2009, 9:125-135.

47. Beraldi D, McRae AF, Gratten J, Slate J, Visscher PM, Pemberton JM: Development of a linkage map and mapping of phenotypic polymorphisms in a free-living population of Soay sheep (Ovis aries). Genetics 2006, 173:1521-1537.

48. Allen JE, Maizels RM: Diversity and dialogue in immunity to helminths. Nat Rev Immunol 2011, 11:375-388.

49. Spits H, Artis D, Colonna M, Diefenbach A, Di-Santo JP, Eberl G, Koyasu S, Locksley RM, McKenzie AN, Mebius RE, Powrie F, Vivier E: Innate lymphoid cells - a proposal for uniform nomenclature. Nat Rev Immunol 2013, 13:145-149.

50. Taylor BC, Zaph C, Troy AE, Du Y, Guild K, Comeau MR, Artis D: TSLP regulates intestinal immunity and inflammation in mouse models of helminth infection and colitis. J Exp Med 2009, 206:655-667.

51. Gutzmer R, Langer K, Lisewski M, Mommert S, Rieckborn D, Kapp A, Werfel $\mathrm{T}$ : Expression and function of histamine receptors 1 and 2 on human monocyte-derived dendritic cells. J Allergy Clin Immunol 2002, 109:524-531.

52. Yoneyama $H$, Harada A, Imai T, Baba M, Yoshie O, Zhang $Y$, Higashi H, Murai M, Asakura H, Matsushima K: Pivotal role of TARC, a CC chemokine, in bacteria-induced fulminant hepatic failure in mice. J Clin Invest 1998, 102:1933-1941.

53. Komiya A, Nagase H, Yamada H, Sekiya T, Yamaguchi M, Sano Y, Hanai N Furuya A, Ohta K, Matsushima K, Yoshie O, Yamamoto K, Hirai K: Concerted expression of eotaxin-1, eotaxin-2, and eotaxin-3 in human bronchial epithelial cells. Cell Immunol 2003, 225:91-100.

54. Tekkanat KK, Maassab H, Miller A, Berlin AA, Kunkel SL, Lukacs NW: RANTES (CCL5) production during primary respiratory syncytial virus infection exacerbates airway disease. Eur J Immunol 2002, 32:3276-3284.

55. Calandra T, Roger T: Macrophage migration inhibitory factor: a regulator of innate immunity. Nat Rev Immunol 2003, 3:791-800

56. Huang RB, Eniola-Adefeso O: Shear stress modulation of IL-1 $\beta$-induced Eselectin expression in human endothelial cells. PLoS One 2012, 7:e31874.

57. Kim I, Morimura K, Shah Y, Yang Q, Ward JM, Gonzalez FJ: Spontaneous hepatocarcinogenesis in farnesoid $\mathrm{X}$ receptor-null mice. Carcinogenesis 2007, 28:940-946.

58. Rosenblum MD, Olasz E, Woodliff JE, Johnson BD, Konkol MC, Gerber KA Orentas RJ, Sandford G, Truitt RL: CD200 is a novel p53-target gene involved in apoptosis-associated immune tolerance. Blood 2004, 103:2691-2698.

59. Voice JK, Dorsam G, Chan RC, Grinninger C, Kong Y, Goetzl EJ: Immunoeffector and immunoregulatory activities of vasoactive intestinal peptide. Regul Pept 2002, 109:199-208.

60. Grainger JR, Smith KA, Hewitson JP, McSorley HJ, Harcus Y, Filbey KJ, Finney CA, Greenwood EJ, Knox DP, Wilson MS, Belkaid Y, Rudensky AY, Maizels RM: Helminth secretions induce de novo T cell Foxp3 expression and regulatory function through the TGF-beta pathway. J Exp Med 2010, 207:2331-2341.

doi:10.1186/1297-9716-44-68

Cite this article as: Gossner et al:: Exploring the abomasal lymph node transcriptome for genes associated with resistance to the sheep nematode Teladorsagia circumcincta. Veterinary Research 2013 44:68.

\section{Submit your next manuscript to BioMed Central and take full advantage of:}

- Convenient online submission

- Thorough peer review

- No space constraints or color figure charges

- Immediate publication on acceptance

- Inclusion in PubMed, CAS, Scopus and Google Scholar

- Research which is freely available for redistribution 